
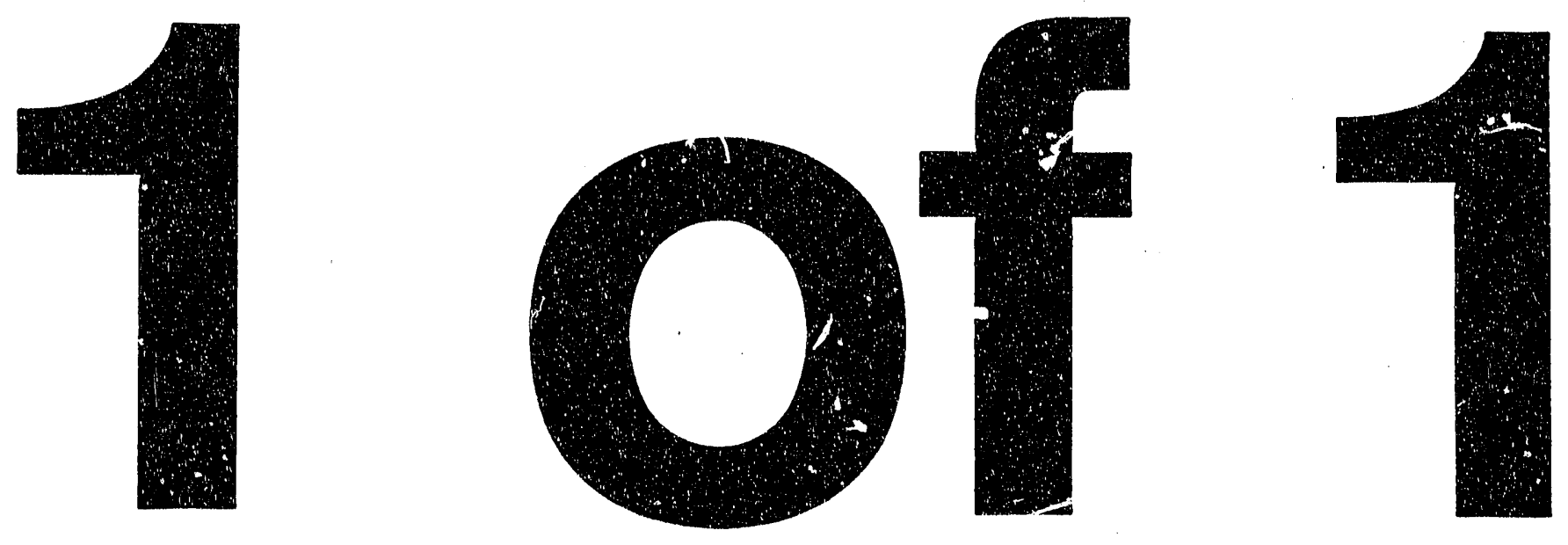


\section{0}

UCRL-ID-119321

\section{NATIONAL STRATEGIC CHALLENGES AND THE ROLE OF LAWRENCE LIVERMORE NATIONAL LABORATORY}

R.A. Al-Ayat

P. L. Chrzanowski

R.W. Werne

January 1995

This is an inform 31 report intended primarily for internal or limited external distribution. The opinions and concluaions stated are those of the author and may or may not be those of the Laboratory.

Work performin uniar the auspices of the U.S. Department of Energy by the Lawrence Livermore National Laboratory under Contract W-7405-Eng- 48. 


\section{DISCLAIMER}

This document was prepared as an account of work sponsored by an agency of the United States Covernment. Neither the United States Government nor the University of Callfornia nor any of their employees, makes any warranty, expres or implied, or assumes any legal liability or responsibility for the accuracy, completeness, or usefulness of any information, apparatus, product, or process disclosed, or represents that its use would no infringe privately owned rights. Reference herein to any specific commercial producto, process, or service by trade name, trademark, manufacturer, or otherwise, does not necessarily constitute ox imply its endoreement, recommendation, or favoring by the United States Government or the University of Callfornia. The views and opinions of authors expressed herein do not necessarily state or reflect those of the United States Government or the University of California, and shall not be used for advertioing or product endorsenent purposes.

This report has been reproduced

directly from the best available copy.

Available to DOE and DOE contractors from the

Office of Scientifil: and Technical Information

P.O. Box 62, Oak Ridge, TN 37831

Prices avallable hom (615) 576-8401, FTS 626-8401.

Avaliable to the public from the

National Technical Inforrnation Service

U.S. Department of Commerce

5283 Pont Royal Ril.

Springfield, VA 22.161

\section{Papercopy Prices}


CONTENTS

Page

CONTENTS

$\begin{array}{lll}\text { ABSTRACT } & \text { ii }\end{array}$

1. INTRODUCTION 1

2. POST-COLD WAR NATIONAL S\&T PRIORITIES

3. APPLYING THE DOE NATIONAL LABORATORIES TO POST-COLD WAR NATIONAL S\&T PRIORITIES 3

4. LLNL'S CHANGING R\&D PORTFOLIO 6

4.1 Diversifying the R\&D Portfolio and Building Partnerships

4.2. Core Competencies and Special Facilities

5. A FRAMEWORK FOR THE FUTURE OF LLNL

5.1 LLNL and Strategic Challenges in Global Security

5.2 LLNL and Strategic Challenges in Global Ecology and Economic Security

5.3 LLNL and Strategic Challenges in Biosciences and Healthcare Technologies

5.4 Basic Science and Science Education at LLNL

6. SUMMARY

REFERENCES

\section{DISCLAIMER}

This report was prepared as an account of work sponsored by an agency of the United States Government. Neither the United States Government nor any agency thereof, nor any of their employees, makes any warranty, express or implied, or assumes any legal liability or responsibility for the accuracy, completeness, or usefulness of any information, apparatus, product, or process disclosed, or represents that its use would not infringe privately owned rights. Reference herein to any specific commercial product, process, or service by trade name, trademark, manufacturer, or otherwise does not necessarily constitute or imply its endorsement, recommendation, or favoring by the United States Government or any agency thereof. The views and opinions of authors expressed herein do not necessarily state or reflect those of the United States Government or any agency thereof. 


\title{
NATIONAL STRATEGIC CHALLENGES AND THE ROLE OF LAWRENCE LIVERMORE NATIONAL LABORATORY
}

\author{
R. A. Al-Ayat ${ }^{1}$, P. L. Chrzanowski², and R. W. Werne ${ }^{3}$
}

Executive Summary

The end of the Cold War was a water-shed event in history-an event that calls for re-evaluation of the basic assumptions and priorities of U.S. national security that have gone essentially unchallenged for nearly 50 years. Central to this re-evaluation are the changing needs for federal Science and Technology (S\&T) investment to underpin national and economic security and the role of the Department of Energy (DOE) national laboratories in fulfilling those needs. The three nuclear weapons laboratories-Los Alamos National Laboratory (LANL), Lawrence Livermore National Laboratory (LLNL), and Sandia National Laboratory (SNL) - are major constituents of DOE's national laboratory system. They helped win the Cold War, and will undoubtedly continue to support U.S. security S\&T requirements. This paper discusses of the role these three laboratories, and LLNL in particular, can play in supporting the nation's S\&T priorities. The paper also highlights some of the changes that are necessary for the laboratories to effectively. support the national S\&T and economic competitiveness agenda. These issues are important to DOE and laboratory managers responsible for the development of strategic direction and implementation plans.

In their pursuit of defense science, related applied science, and supporting basic science during the Cold War, the nuclear weapons laboratories contributed to major advances in a wide range of areas, from computer technology and nuclear physics to chemistry and materials science, biotechnology and environmental research. Each of the laboratories constitutes a unique, major investment that can tackle high-risk, long-term R\&D projects leading to engineering or prototype development. Typically, they have focused on nationial. priority $S \& T$ projects that are beyond the investment horizon of industry and are ( $k$ ) multifaceted for universities. As such, breakthrough S\&T and large public R\&I) challenges-supporting both national security and economic security objectives-reprexni an important niche for these DOE national laboratories.

LANL, LLNL and SNL are more than nuclear weapons laboratories; they are center fir the pursuit of large-scale applied science. Well before the end of the Cold War, LLNL beg'an I" diversify its R\&D portfolio through dual-benefit activities that built on and reinforcid the Laboratory's core competencies. The capabilities and experience gained from these cllurr provide the foundation for the Laboratory's future. LLNL's recently-issued vision staltime'nt. Framing the Laboratory's Future [1], identifies three national strategic challenges fior whw the laboratory is particularly well qualified to make an impact. They are: global (militar , security; global ecology and economic security; and biosciences and healthcare technulugk

The diagram in Figure 1 provides a framework for these S\&T challenges. At the heirt " It the diagram are some of the core competencies and special facilities at LLNL. Ihe

\footnotetext{
${ }^{1}$ Director, Center for Economics and Systems Studies

${ }^{2}$ Director, Center for Security and Technology Studies

${ }^{3}$ Associate Director for Engineering and Technology Transfer
} 
capabilities/facilities, coupled with LLNL's expertise in basic science research, provide the Laboratory with a solid foundation to pursue $R \& D$ efforts in the three areas specified in LLNL's vision statement-shown in the next layer of the figure. Finally, the outermost layer emphasizes the importance of establishing partnerships with other laboratories, other government agencies, universities, and industry.

To meet the challenges discussed here, several issues need to be addressed. These include:

- Increasingly, dual benefit s(civilian and military) must be derived from the $R \& D$ pursued in major programs which, in turn, must provide necessary institutional support. The array of core competencies and special facilities and capabilities at the nuclear weapons laboratories are the product of major investment by DOE Defense Programs during the Cold War. Today, this investment is increasingly providing benefits to the civilian sector through industrial partnering; it is also providing the basis for growth into areas that take advantage of and reinforce existing programs. Reliance on the laboratories' R\&D to meet trategic S\&T challenges calls for continuous reinvestment in the laboratories. ieinvestment includes institutional support for broad-based physics, chemistry and materials science, and engineering prográms. A lack of institutional support would lead to expenditure of the capital at the laboratories-core competencies, state-of-the-art facilities, and cutting-edge R\&D. As a consequence, pursuit of multiple--benefit activities as a funded element of major programs is a "win-win" arrangement. It provides valuable institutional support, maximizes the benefits to the nation, helps reinforce and strengthen core competencies, and develops and maintains skills of technical staff that carry responsibilities for stockpile stewardship.

- $R \& D$ must be managed in a DOE laboratory system. In an era of limited resources, the government must balance the needs for cooperation and competition and take maximum advantage of specific strengths of each laboratory while ensuring peer review. The laboratories, too, must meet the challenge of better integrating their activities and capabilities to capture the best aspects of cooperation and competition. Steps currently being taken to forge the efforts of LLNL, LANL, and SNL into a highly integrated nuclear weapons stockpile stewardship program is an encouraging example of the way the laboratories must work together in other R\&D areas.

- The laboratories' customer base and research agenda must continue to change to meet post-Cold War priorities. As the DOE national laboratories refocus their R\&D activities-in part, to support national economic competitiveness-they must expand their customer base and explore ways to work with other federal and state agencies. Some channels for collaboration already exist. At the federal level, for example, the laboratories have used "Work for Others" (WFO) agreements to perform R\&D for other government agencies. However, these activities have been limited in size and scope, and negotiating a WFO agreement rernains a time-consuming process. To be effective, DOE laboratories must become more easily accessible to work in collaboration with various federal, state, and regional entities.

- The laboratories must continue to build their working relationship with industry. Over the past few years, the laboratories have begun to forge new alliances with industry. The 1989 National Competitiveness Technology Transfer Act (NCTTA) authorized DOE and its national laboratories to enter into Cooperative Research and Development Agreements (CRADAs) for cost-shared, market-driven collaborative research with U.S. industry. In general, laboratory scientists and engineers have been enthusiastic about these partnering opportunities, and industry interest is high. However, several factors have limited the 
effectiveness of the CRADA mechanism. To improve support of national economic competitiveness, the laboratories must provide even greater access to industrial partners, must continue to simplify the processes for establishing collaborative agreements, and must explore additional mechanisms for collaboration.

To address these and other related issues, organizational changes are underway to align program management structure so that LLNL can better apply its special strengths to these S\&T strategic challenges. In areas where there are special strengths, centers of excellence have been formed to coordinate strategies and activities, and as particular mission responsibilities expand, further organization changes may become necessary. In addition, the various directorates at LLNL are in the process of:

- Developing road maps and plans of action to apply the special strengths of the Laboratory to specific S\&T strategic challenges.

- Implementing improved processes to enable the Laboratory to work cooperatively with federal, state, and local agencies and the private sector in a more efficient and costeffective manner.

Already engaged in projects in new mission areas, LLNL scientists and engineers are demonstrating their ability to tackle post-Cold War strategic challenges facing the nationchallenges in applied science that require long-term, multidisciplinary efforts; challenges that take advantage of the Laboratory's core competencies, special capabilities and unique facilities. In short, LLNL should not be viewed solely as a defense laboratory, but as a premier national resource for medium- and large-scale science and technology demonstration. And to that end, LLNL is reaffirming its commitment to its history of public service in support of the nation's S\&T priorities. 


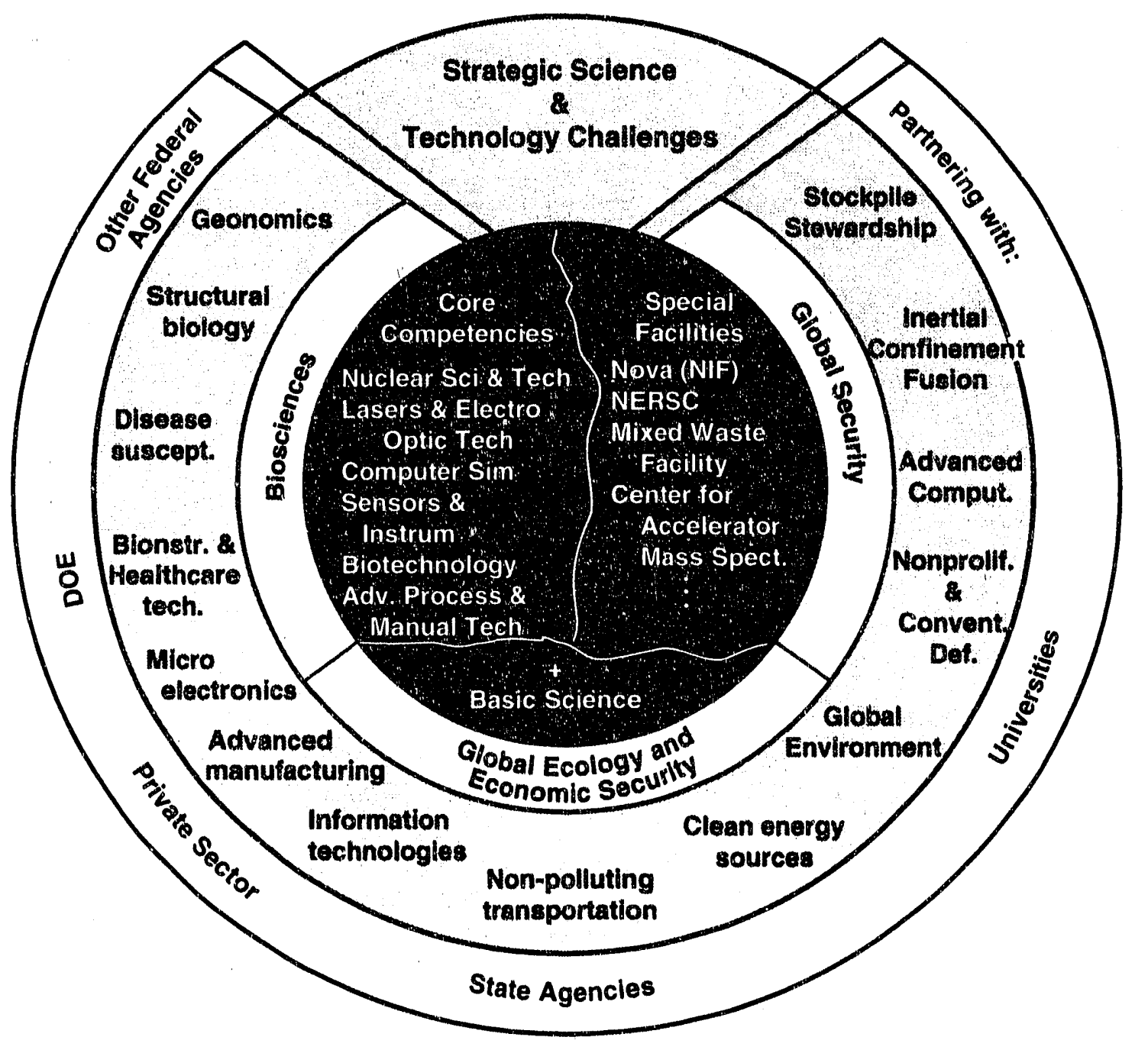

Figure 1. A Framework for LLNL future contributions to post-Cold War strategic S\&T challenges. 


\section{NATIONAL STRATEGIC CHALLENGES AND THE ROLE OF LAWRENCE LIVERMORE NATIONAL LABORATORY}

\section{INTRODUCTION}

With the end of nearly five decades of military competition between the superpowers, this nation's science and technology (S\&T) investment strategy is undergoing major reevaluation. In 1992, some $\$ 68.2$ billion was invested by the Federal Government in research and development (R\&D), of which 60\% was defense-related. President Clinton's goal is to bolster U.S. industrial competitiveness by increasing the nondefense portion of the Federal $R \& D$ investment. A major element in the national debate on reprioritizing public R\&D expenditures is the future of Department of Defense (DOD) and Department of Energy (DOE) national laboratories, which have been a major part of the U.S. S\&T infrastructure since the Cold War began. A key question is the extent to which these laboratories can contribute to today's changing national S\&T challenges. The answers to this question, and others, will no doubt result in significant change for these laboratories.

Of particular interest are the three weapons laboratories: Lawrence Livermore National Laboratory (LLNL), Los Alamos National Laboratory (LANL), and Sandia National Laboratories (SNL), a major component of the DOE national laboratory system. Scientific and engineering talent was assembled at these laboratories to advance nuclear weapons technology during the Cold War era. Today, each of these laboratories constitutes a unique, major investment by the Federal Government-an investment that can, and should, pay continuing dividends for both the defense and civilian sectors.

This paper explores the role the DOE weapons laboratories can play in support of the nation's post-Cold War strategic S\&T challenges-with particular focus on changes underway at LLNL. It builds upon the recently issued vision statement Framing the Laboratory's Future, which identifies three major post-Cold War mission areas for LLNL: global (military) security; global ecology and economic security; and biosciences and healthcare technology. These mission choices are based on national S\&T needs and the existing strong foundation of LLNL core competencies, special facilities, and ongoing relevant programs. Over the years, LLNL has evolved from a nuclear weapons laboratory to a multiprogram laboratory. With the end of the Cold War, the pace of change has accelerated. Today, nuclear weapons R\&D comprises less than $25 \%$ of the Laboratory's budget-a decline of more than a factor of two since 1987, with further shrinkage in FY 1995 . In contrast, LLNL programs have expanded in several areas, including lasers, environmental research, and collaborative R\&D with U.S. industry.

The expansion of LANL, LLNL, and SNL into other mission areas has followed from and taken advantage of their unique collection of strengths-their multidisciplinary approach to problem solving, their rich array of core competencies, and their special facilities. They are able to tackle high-risk, long-term R\&D projects leading to engineering or prototype development that are beyond the investment horizon of industry and are too multifaceted and large-scale for universities. As such, breakthrough S\&T and large public R\&D challengessupporting both national security and economic security objectives-represent an important niche for these DOE national laboratories. 
It is increasingly recognized that future LLNL programmatic activities will depend on our ability to work in partnership with other laboratories, the DOE and other government agencies, universities, and private industry. Organizational changes have been instituted to better align the Laboratory's program management structure and to help focus our efforts on post-Cold War S\&T challenges. Already, for example, LLNL has expanded its role in support of U.S. industry and has become one of the leaders among DOE laboratories with more than $100 \mathrm{R} \& \mathrm{D}$ collaborations with some 150 industrial partners.

\section{POST-COLD WAR NATIONAL S\&T PRIORITIES}

In the post-Cold War world, the U.S. faces a changing spectrum of security threats-both military and nonmilitary. In the military arena, the likelihood of global nuclear war has waned, but the prospect of proliferation of weapons of mass destruction by regional powers presents serious new problems. At the same time, stewardship of an enduring nuclear stockpile in the absence of nuclear testing remains a critical part of the U.S. strategy to lead Russia to make further nuclear stockpile reductions while hedging against unanticipated changes for the worse. In addition, the U.S. must strive to maintain technical superiority of its conventional forces during a period of tightening defense budgets. Advances in S\&T are key to meeting these challenges.

As for nonmilitary threats, there is an increasing need for S\&T advances to tackle economic security and environmental challenges. The nation needs abundant clean sources of energy. non-polluting transportation, advanced manufacturing technologies to improve productivity and reduce waste, investment in human capital, scientific breakthroughs that can improve the common welfare, and remediation of environmental problems. In short, the U.S. must makc strategic R\&D investments to sustain economic growth in an increasingly global market. place while protecting the environment. Research and development has been a source of strength for the U.S. economy, and today, more than ever, R\&D investments are needed (1) ensure a sustainable future. At issue are how to make the investrnent and where to invers.

Research and development efforts directed at meeting national challenges must have hulh a market base and a public component. The private sector should continue to do what 11 den." best-seek R\&D investments that offer the prospect of a return to its shareholders. The $x$ investments tend to have a near-term focus, entail more "development" than "research." and constitute low- to medium-risk ventures. The public sector R\&D investment hould complement that of the private sector by supporting the infrastructure and by addre $\cdots$ inf strategic S\&T challenges that are long-term, high-risk, and/or result in public benefiis -hossci by all. Infrastructure support includes investments in basic sciences, science educallun. and public goods such as environmental research or support for the information superhighu at

Selection of strategic longer-term S\&T projects requires careful consideration by the $1 \cdot(k \cdot 1.1$ Government. The public R\&D investment portfolio, as with a stock poris 10, must halune: risk against payoff. A prudent strategy - which cannot be devised without privalc u'wir input-entails diversification across industrial sectors and across time horizons and $11 \mathrm{~h}$ categories. It must also maintain a balance between efforts that advance disciplin.ur knowledge and efforts that couple directly to nore immediate industrial/comminc $1,1,1$ interests. Moreover, the S\&T project-selection strat gy should take advantage of invermm.nk already made in the nation's R\&D infrastructure that can contribute effectively 11 m 1 h defense and civilian needs. 


\section{APPLYING THE DOE NATIONAL LABORATORIES TO POST-COLD WAR NATIONAL S\&T PRIORITIES}

The sizable investment in the DOE national laboratories is an asset not to be squandered. Each of these laboratories has unique facilities and an invaluable knowledge base embodied in its scientific staff. Furthermore, as the laboratories continue to have nuclear-weaponsrelated responsibilities, they are not likely to disappear. The question, therefore, is how to best use the talent at these laboratories to tackle a broader $R \& D$ agenda in support of the nation's S\&T challenges. This is particularly important now as major U.S. corporations continue to downsize and/or close their research facilities. Businesses recognize that longterm research is necessary for future products and markets, but more immediate demands preclude them from investing resources accordingly. In short, it is in the long-term interests of this country to "keep the $R \& D$ pipeline full." A vigorous $R \& D$ program at the DOE national laboratories can help ensure that this goal is met.

Focusing the DOE laboratories on strategic $S \& T$ and public $R \& D$ challenges plays directly to their strengths-their multidisciplinary approach to problem solving, their manifold core competencies, and their special facilities. Nonetheless, several key issues must be addressed:

- $R \& D$ must be managed in a DOE laboratory system with overlapping capabilities and core competencies. In an era of limited resources, it is important to recognize the specific strengths resident at each laboratory. Parceling out program responsibilities is not simply a matter of identifying which laboratory is the "environmental lab," the "weapons lab," or (possibly) the "transportation lab." Some R\&D projects should be assigned based on unique facilities at a particular laboratory and/or special capabilities. Other projects should be pursued through partnerships among the laboratories (and others) with requisite capabilities. Yet other projects should be granted on a competitive basis to stimulate creativity and innovation.

Moreover, the Government will be challenged to balance the needs for cooperation and competition, to take maximum advantage of unique capabilities while ensuring peer review, and to provide prudent management oversight while allowing pursuit of novel ideas that may deviate from project definition. The laboratories, too, must meet the challenge of better integrating their activities and capabilities to capture the best aspects of cooperation and competition. Steps currently being taken to forge the efforts of LLNL, LANL, and SNL into a highly integrated nuclear weapons stockpile stewardship program is an encouraging example of the way the laboratories need to work together.

- The laboratories' customer base and research agenda must continue to change to meet post-Cold War challenges. Since their inception, the DOE national laboratories have worked with a few federal agencies, principally the DOE and the DOD. Their primary focus has been "nuclear"- nuclear weapons, fusion energy, and environmental issues associated with hazardous or radioactive materials. In these areas, the laboratories have proven that they can work in collaboration with universities, other research institutions, industry, and government to solve large-scale technology problems of national importance. As the DOE national laboratories refocus their R\&D activities-in part, to support national economic competitiveness-they need to expand their potential customer base and to explore ways of working with other federal and state agencies. 
Some channels for collaboration already exist. At the federal level, for example, the laboratories have used "Work for Others" (WFO) agreements to perform R\&D for other government agencies such as the Environmental Protection Agency, Department of Transportation, National Institutes of Health, and Nuclear Regulatory Commission. However, these activities have been limited in size and scope, and negotiating a WFO agreement remains a time-consuming process. To be effective, DOE laboratories must become more easily accessible to address national R\&D problems in energy, environment, transportation, education and health through collaborations with federal, state, and regional entities.

- Increasingly, dual benefit s(civilian and military) must be derived from the $R \& D$ pursued in major programs at the nuclear weapons laboratories, which, in turn, must provide necessary institutional support. The array of core competencies and special facilities and capabilities at the nuclear weapons laboratories are a consequence of the investment made by DOE Defense Programs in these facilities during the Cold War. This investment is increasingly providing benefits to the civilian sector through technology transfer, and it is providing the basis for growth into areas that take advantage of and reinforce existing programs. In general, continuing reliance on the laboratories' R\&D to meet strategic $\mathrm{S} \& \mathrm{~T}$ challenges calis for continuous reinvestrient in the laboratories.

Reinvestment includes support for broad-based physics, chemistry and materials science, and engineering programs, which will be needed to address the complex issues that will arise for an aging stockpile. These broad-based scientific and engineering activities both provide the basis for $R \& D$ on $S \& T$ strategic challenges and require institutional support. Such institutional support derives from and requires stable funding of major anchor program(s) at the laboratories (such as the weapons program). Without major customers and sustained programs, the laboratories would become "job-shoppers". Moreover, a lack of institutional support would lead to expenditure of the capital at the laboratories-core competencies, state-of-the-art facilities, and cutting-edge R\&D-without reinv stment. As a consequence, pursuit of multiple-benefit activities as a funded element of major programs is a "win-win" arrangement. It provides valuable institutional support, maximizes the benefits to the nation, helps reinforce and strengthen core competencies, and develops and maintains skills of technical staff that carry responsibilities for stockpile stewardship.

- The laboratories must continue to build their working relationship with industry and improve the collaboration mechanisms. Over the last few years, the laboratories have begun to forge new alliances with industry through cooperative efforts to identify where short-term technology insertions, medium-term technology maturation's, and long-term development might bolster U.S. global competitiveness. With passage of the 1989 National Competitiveness Technology Transfer Act (NCTTA), DOE and its national laboratories were authorized to enter into Cooperative Research and Development Agreements (CRADAs) for cost-shared, market-driven collaborative research with U.S. industry. With more than 1000 CRADAs in place, the laboratories have moved aggressively to carry out this new mission. Technology transfer projects are underway in the semiconductor, biotechnology, and automotive industries, as well as in industries emerging around high-density energy storage devices, environmental remediation and waste minimization technologies, and advanced lithography systems for the semiconductor industry. Overall, the laboratories are actively supporting the technology neecis of small businesses and are teaming with major industries through purposeful, focused individual projects and consortia. 
Although it has been a learning process, CRADAs have become an effective mechanism for industry to access the technology infrastructure of the national laboratories. So far, laboratory scientists and engineers have been enthusiastic about these partnering opportunities, and industry interest has been high, as measured by the demand for CRADAs. However, several factors have limited the effectiveness of the CRADA mechanism, and much room for improvement remains. To support national economic competitiveness effectively, the laboratories must provide greater access to industrial partners, must continue to simplify the processes for establishing collaborative agreements, and must explore additional mechanisms for collaboration, including personnel exchanges and facility and equipment use agreements. Partnerships often require quick response, which at times has been hampered by lengthy federal procedures. To be useful, the laboratories need greater flexibility and more discretion to enter into selected partnerships with minimal DOE oversight.

To serve as a national asset and ensure the success of industrial collaborations, the laboratories must work with industry leaders to clearly define industry's needs and expectations. Joint efforts with major industry sectors can lead to the development of road maps to identify technology areas where the laboratories' competencies can be appropriately applied. Industry sector initiatives underway include those with the Semiconductor Industry Association, USCAR (the "Big Three" auto companies), AMTEX, and major consortia in the oil and gas industry. Many collaborative projects have resulted from industry carefully examining technology capabilities at the various laboratories, defining projects which they wished to pursue, and then selecting the best qualified laboratory partner for carrying out the necessary development and demonstration activities.

In addition, special attention has been given to small businesses. Small firms often lack the facilities and technical expertise needed to succeed, yet they play an important role in supporting economic recovery and in creating large numbers of high-paying jobs. Through DOE's Small Business Initiatives Program, LLNL and the other national laboratories have provided technical assistance to more than 400 small enterprises, affording them access to facilities and expertise that otherwise would be unavailable.

- The laboratories must pursue ways to help improve U.S. industrial competitiveness without competing with the private sector. When there are "winners"-such as in competing for a limited number of CRADA opportunities-there are also "losers". There will be fewer losers as more resources are devoted to CRADAs and other collaborative efforts. Nevertheless, partnerships between laboratories and industrial firms may become viewed as successes by the winners and as unfair competition by the losers, particularly if management processes are not transparent.

Many firms have shown interest in collaborations, in part because the large multidisciplinary staff at a national laboratory is not affordable by most private-sector R\&D organizations. As the laboratories enter into cooperative arrangements, care must be taken to maintain fairness of opportunity and to ensure that federal support is equally available to broad industry participation. Such collaborations may be most successful, therefore, when the partners are industrial consortia and/or when the joint activity pursues a breakthrough technology that will provide broadly distributed economic benefits.

More importantly, the laboratories must avoid competition with the private sector, especially with firms in contract R\&D. Undoubtedly, this goal will become increasingly difficult as the laboratories endeavor to become more responsive to the needs of the 
marketplace. Still, the laboratories must strive to undertake only those S\&T projects where the laboratories" "value-added" is unique compared to that available elsewhere in the private sector. In this regard, a focus on solutions to long-term problems that have been identified by industriai-sector partners can help.

\section{LLNL'S CHANGING R\&D PORTFOLIO}

\subsection{Diversifying of the R\&D Portfolio and Building Partnerships}

Well before the end of the Cold War. LLNL began to change by diversifying its R\&D portfolio through the pursuit of dual-benefit activities that built upon and reinforced the Laboratory's core competencies. The capabilities and experience gained from these efforts provide the foundation for the Laboratory's future. The recently issued LLNL vision sidtement, Framing the Laboratory's Future, is a major step in the planning process. It identifies national strategic S\&T challenges where LLNL is particularly well qualified to make an impact, and organizational changes are underway to align the Laboratory program management structure accordingly. The next step in the process is the development of road maps and plans of actions to apply the special strengths of the Laboratory to specific S\&T strategic challenges. In many areas where there are special strengths, centers of excellence have been formed to coordinate strategies and activities.

It is the special strengths that distinguish LLNL from other R\&D institutions that will be key to the Laboratory" $s$ ability to forge new or expanded missions. Clearly, the assignment of major R\&D programs to LLNL is most compelling when the research effort builds on what already exists at the Laboratory-its core competencies, special capabilities and facilities, and ongoing successful progiams. This foundation is the basis for the broad framework defined in Framing the Laboratory's Future and for the ideritification of three research areas for LLNL: global security, global ecology and economic security, and biosciences and healthcare technologies. In each of these areas, there are many strategic S\&T challenges that address important national needs. LLNL's specific role in tackling these challenges will depend on to be-developed road maps and plans of action to contribute to solutions, working in partnership with other laboratories, government agencies, universities, and private inciustry.

L.LNL will be able to build partnership R\&D programs upon an established experience base in working with others. Currently, most work for others at LLNL (about $20 \%$ of the Laboratory's budget) is for the Department of Defense. In the future, efficient use of federal R\&D capabilities to meet national needs may well lead to LLNL to working in closer partnership with a variety of federal and state agencies, such as the Department of Commerce, the Department of Transportation, federal and state Environmental Protection Agencies, and the National Institutes of Health. This new customer base will necessitate effective coordination and communication between agencies. It will also require closer working relationships with other laboratories sharing R\&D responsibilities with LLNL.

The Laboratory is also growing more experienced in partnering with industry. Increasingly, since passage of the NCTTA, LLNL has pursued conperative R\&D activities with industrial partners to bolster U.S. economic competitiveness in the global marketplace. In addition, Laboratory talents continue to be applied in seeking technological breakthroughs in response to industrial S\&T challenges. Current multi-benefit activities at LLNL include spin-offs to industry from programmatic research and partnerships with U.S. industry, such as licensing 
arrangements and CRADAs. The Laboratory is one of the leaders in DOE partnership arrangements, having over the past three years signed more than 100 CRADAs with some 150 industrial partners totaling more than $\$ 350$ million. Many of the CRADAs take advantage of special LLNL capabilities in: manufacturing and production technologies; advanced lasers; advanced materials; microelectronics packaging and processing; and computer modeling, simulation and information storage.

\subsection{Core Competencies and Special Facilities}

The foundation of LLNL's R\&D portfolio is the Laboratory's core competencies and special facilities. Many of the core competencies of the DOE nuclear weapons laboratories are similar by design. LLNL and LANL were intended to compete in nuclear weapon work as a way to spur innovation and provide peer review. Over the years, the two laboratories (and SNL) have developed an extensive set of core competencies that underlie their ability to execute a broad range of scientific and technical programs. Six core competencies are central to most LLNL projects:

- Nuclear science and technology-for the development and stewardship of nuclear weapons and the harnessing of thermonuclear and fission energy for commercial power.

- Lasers and electro-optic technologies -including construction of the world's largest laser (Nova), development of the AVLIS (Atomic Vapor Laser Isotope Separation) system for commercial use, and application of laser and electro-optic technologies to a wide range of civilian and defense needs.

- Computer simulation of complex systems-use of world-class computations facilities and computer modeling as a first resort in the examınation and evaluation of new concepts and systems.

- Advanced sensors and instrumentation-development of state-of-the-art instrumentallon for detecting, measuring, and analyzing a wide range of physical events for such applications as nonproliferation, environmental monitoring, and space-based scicnufic measurement.

- Biotechnology - to understand health issues at the molecular level, including the sudy "If ge retic susceptibility, mapping and sequencing the human genome, and developing ins truments and techniques used worldwide in biologicai research.

- Advanced process and manufacturing technology-to support innovative applied xinc: efforts in chemical, biological, and photon processes; advanced materials; precisiun engireering; microfabrication; nondestructive evaluation; and complex-system cuntrul and automation.

These core competencies-initially the product of LLNL's national security effor hatc enabled the Laboratory to grow into a multiprogram, multidisciplinary national renurc: capable of contributing to a much broader range of national needs. Conversely. Ihe Laboratory's work in these other areas has provided cross-fertilization in both concepi and hardware, and has enhanced and enriched our core competencies.

Other factors that help differentiate the DOE weapons laboratories from other rescurch installations as well as from each other are the special capabilities and facilities that uppirt 
each laboratory's programs. Examples of these unique major facilities and research centers at LLNL include:

- The Nova laser facility and the planned National Ignition Facility

- The National Energy Research Supercomputer Center (NERSC) and the Livermore Computer Center

- The High-Explosives Application Facility and the Flash X-Ray Facility

- The Fusion Engineering International Experimental Facility

- The Mixed Waste Management Facility (under construction)

- Livermore Center for Advanced Manufacturing and Productivity

- The Large Optics Diamond Turning Facility

- The Center for Human Genome Research

- The Microtechnology Center

- The Center for Accelerator Mass Spectrometry

- Other LLNL research centers and institutes that work collaboratively with universities throughout California, including the Institute for Geophysics and Planetary Physics and the Plasma Physics Research Institutes.

\section{A FRAMEWORK FOR THE FUTURE OF LLNL}

The diagram in Figure 1 showing the three mission areas identified in LLNL's vision statement relevant to post-Cod War strategic S\&T challenges provides a convenient framework for discussing future activities at the Laboratory. Subsequent subsections deal with each of the mission areas, followed by a final subsection on the role of basic science and science education at the Laboratory.

It should be mentioned, however, that the diagram has some limitations as a guidepost for discussing missions and strategic S\&T challenges at LLNL. For instance, the figure fails to highlight the multiple-use benefits from many of the program activities, nor does it depict in any detail the way core competencies and special facilities support multiple-program efforts. An example of a future program activity and unique facility that will have multiple-use benefits is the National Ignition Facility (NIF). When constructed, it will support global security through the stockpile stewardship program; global ecology and economic security through technology development needed for construction; the advancement of science through the use of NIF; and the contribution the NIF makes to the goal of fusion as a clean energy source. An example of a core competency that supports multiple programs is computer science and simulations. Other examples of multi-benefit entities in Figure 1 are discussed in the following subsections. 


\subsection{LLNL and Strategic Challenges in Global (Military) Security}

With the end of the Cold War, the world is a much safer place. Yet challenges related to nuclear weapons persist. Nuclear dangers are posed by the large nuclear arsenal remaining in the former Soviet Union and by the threat of proliferation of weapons of mass destruction. To maintain global security, the United States must:

- Dismantle the nuclear weapons eliminated through arms control agreements and dispose of the resulting nuclear inaterials.

- Develop and implement a stockpile stewardship program that ensures the safety, reliability, and effectiveness of weapons remaining in the inventory, and are required to preserve the ability to reccistitute necessa.y capabilities and forces.

- Respcnd effectively to the threat of nuclear proliferation.

The DOE nuclear weapons laboratories have major responsibilities in each of these military security priorities, which are substantially different from the Cold War mission of the laboratories. These responsibilities demand change at the laboratories, even in their nuclearweapons eff srts and provide $\mathbf{S} \& \mathrm{~T}$ challenges requiring innovative solutions. Excess nuclear materials frum weapons must be disposed of in a secure and environmentally acceptable manner. In addition, the laboratories must now rely on predictive capabilities, non-nuclear experiments, and computer simulation without nuclear testing in their mandate to ensure a safe and reliable nuclear stockpile. Finally, the laboratories must pursue advanced technologies for detection, monitoring, and verification to support the nation's nonpioliferation goals.

Reductions in fundine for nuclear weapons R\&D continues to be a driver for change at the labcratories as they define a nuclear-test-free stockpile stewardship program. Between 1987 and 1994, LLNL ausorbed a decline of more than a factor of two in nuclear weapons R\&D funding support. The three nuclear weapons laboratories are working with DOE to design and implement a coordinated stockpile stewardship program, consolidating efforts and facilities as appropriate and collaborating wherever possible. In this partnership, lead!aboratoiy responsibilities will reside at Livermore in several areas because of LLNL's special capabilities. Three areas of LLNL $g^{\prime}$ obal security efforts are particularly noteworthy because of their dual benefits:

- Inertial Confinement Fusion (ICF). This is a prominent examnle of where LLNL has lead responsibility. The next step in ICF beyond L,LNL's Nova laser facility is the National Ignition Facility (NIF). The conceptual design report for NIF has been completed and the project has received Key Decision One approval. An important feature of NIF is that it serves multiple national strategic objectives:

- NIF is crucial to the future stockpile stewardship program. The facility will provide well diagnosed experimental data to calibrate weapons physics models. It will also attract to the Laboratory top-notch scientists needed for continuing cerificicition of the safety and reliability of the U.S. nuclear stockpile.

- NIF also contributes to the goal of energy and economic security for the U.S. and the world in the 2.1 st century. Demonstration of net fusion energy gain in the laboratory will be an essential step for the development of inertial fusion for civilian power production. In addition, development of NIF will advance the state-of-the-art in high- 
precision optics and many other laser-related technologies, which can contribute to the competitiveness of U.S. industry.

- NIF will provide a unique laboratory for high-energy-density physics, offering opportunities for greater scientific achievements and dual-benefit projects than those possible with Nova. Recent achievements with Nova have advanced science and technology on many fronts-astrophysics, x-ray physics, computational physics, and diagnostic techniques. Nova is central to dual-benefit efforts estimated at $\$ 100$ million.

- Advanced computing. An important responsibility shared by all DOE nuclear weapons laboratories is the advancement of computer science. Improved computer modeling capability is critical to future stockpile stewardship without nuclear testing. Investments are being made in state-of-the-art computers, including the recent acquisition by LLNL of a major massively parallel processor (MPP) computer, the Meiko. Computational tools are being developed to take advantage of this enhanced MPP capability. These tools will be widely applicable for both defense and commercial purposes. Presently, LLNLdeveloped computer models are being used by the private sector. For example, our structural dynamics simulation code, DYNA-3D and its derivatives, is estimated to be saving U.S. industry more than $\$ 100$ million/year in reduced product design and testing costs.

- Nonproliferation and conventional defense. Nonproliferation, conventional defense, and related dual-benefit projects at LLNL take special advantage of and reinforce the Laboratory's nuclear technology base. Nonproliferation project areas include: intelligence analysis of nuclear weapons activities worldwide, support of international inspections, cooperative activities with the former Soviet Union, development of sensor technologies for detecting and monitoring nuclear weapons activities, and development of technologies for neutralizing nuclear proliferation threats.

Our conventional defense activities seek innovative solutions to R\&D problems for DOD and the defense industry. Some of these activities take advantage of Laboratory expertise in sensor technologies and/or LLNL-developed computer simulation capabilities; other activities benefit from our expertise in energetic materials. LLNL, with its Energetic Material Center and High-Explosives Application Facility, has been designated lead nuclear weapons laboratory in this area. Moreover, this expertise contributes to stockpile-stewardship issues related to weapons safety and the aging of explosives and other organic compounds in weapons.

\subsection{LLNL and Strategic Challenges in Global Ecology and Economic Security}

A major challenge facing the world is how to ensure sustainable economic growth while keeping the demands of production and consumption from harming the environment. Achieving such giobal ecological balance and economic security requires:

- A fundamental understanding of the global environment, including the benefits, risks, and costs of future activities and options to clean up existing environmental problems.

- Sources of energy that are abundant, safe, and clean.

- Transportation systems that do not pollute. 
- Advanced manufacturing and information technologies, in part to support production and consumption processes that use resources wisely, recycle materials officiently, and dispose of wastes safely.

This newly emerging challenge requires the best efforts of the world's scientific institutions. LLNL has begun developing technologies that will support U.S. leadership in this worldwide endeavor. R\&D at LLNL can assist U.S. industry in complying with government environmental standards and regulations, and at the same time, help the U.S. lay claim to a large share of the global market for environmental technologies and services, which is estimated to exceed $\$ 300$ billion annually by the beginning of the 21 st century. We are also pursuing $R \& D$ on clean sources of energy, non-polluting transportation, and a variety of advanced manufacturing and information technologies:

- Global environment. LLNL efforts in environmental modeling, assessment, and remediation are based on decades of experience dealing with radiological and toxic hazards associated with nuclear weapons. It is a multidisciplinary problem-suitable for a national laboratory - that requires expertise in computer modeling together with experimental validation, detection and monitoring technologies and equipment, risk analysis, the handling of hazardous materials (including necessary robotics), and costefficient cleanup and remediation technologies. LLNL is pursuing environmental technologies for its own on-site cleanup as well as for much larger tasks within the DOE complex. Environmental work at LLNL-more than $\$ 100$ million in FY 1993-is primarily supported by DOE. Other sponsers include DOD, EPA, and CalEPA.

LLIVL is a world leader in environmental modeling and model validation. The Laboratory developed the Atmospheric Release Advisory Capability (ARAC) in the 1980 s for DOD. ARAC continues in operation, providing real-time regional and global predictions of the transport, diffusion, and deposition of radionuclides released into the atmosphere. LLNL also has major responsibilities in the international global climate modeling effort. The Laboratory's Program for Climate Model Diagnosis and Intercomparison is leading the Atmospheric Model Ihtercomparison Project, the largest internationally coordinated test of atmospheric models ever undertaken. Several centers of excellence contribute to LLNL's special capabilities in assessing environmental issues. These include: the Center for Accelerator Mass Spectrometry; the Forensic Science Center; and the Risk Sciences Center, a collaborative effort with other University of California researchers.

The Laboratory also has many ongoing partnerships with universities and industry in the areas of waste minimization, treatment, and disposal. Presently, LLNL is pursuing projects in soil and groundwater cleanup, detection and characterization of underground contaminants, waste processing and waste minimization, and robotics for remote handling of hazardous materials. In addition, the Laboratory has received approval to begin construction of the Mixed Waste Management Facility. This user facility will serve as a national testbed for scientists 10 demonstrate alternative treatment technologies to the incineration of hazardous waste and mixed (both radioactive and toxic) waste.

- Clean sources of energy. LLNL activities investigating alternatives to burning fossil fuels as a source of energy fall into iwo broad categories: nuclear energy-primarily fusion, but also fission-and alternative energy sources. Our role in nuclear energy research is well established through decades of experience, major specialized facilities, and large ongoing R\&D programs. The largest of these is LLNL's work on Inertial Confinement Fusion (ICF). The Laboratory has designed and built six major laser 
systems for ICF research, the most recent being Nova. The next-generation National Ignition Facility (NIF) is important because of its role in stockpile stewardship (noted earlier) and energy security.

LLNL also plays an integral role in the international collaboration to develop magnetic fusion energy. Here, the Laboratory's special expertise and facilities support many partnership efforts: experiments using existing tokamaks, design of the next generation of tokamaks, numerical simulations of magnetic fusion, and design and testing of superconductors for future tokamaks.

Our expertise in fission energy ranges from the safe operation of reactors, to all aspects of reactor fuel materials and nuclear wastes, to systems and procedures for the safe handling and storage of nuclear material, to security of nuclear facilities. The Laboratory works closely with the DOE, the Nuclear Regulatory Commission, and other U.S. agencies to develop standards and provide objective reviews and analyses in the fission energy arena.

Another major work project has been the development of Atomic Vapor Laser Isotope Separation (AVLIS) for uranium enrichment. This 20-year, \$1-billion R\&D effort is now undergoing commercialization. AVLIS will permit a smooth shift to a uranium enrichment technology that is more efficient and promises to lower production costs.

- Non-polluting transportation. National transportation problems and their impact on U.S. economic competitiveness are a major concern at the state and federal levels. Improving the efficiency of transportation and reducing the nation's dependence on fossil fuels also present major challenges. The importance of the problem is reflected in the establishment of the National Clean Car/New Generation Vehicle Initiative and the funding for transportation research (more than $\$ 100$ billion over six years) provided by the Intermodal Surface Transportation Efficiency Act of 1991. The Laboratory is pursuing several innovative concepts and important modeling capabilities pertinent 10 the transportation sector. These efforts include investigation of innovative alternatives 10 the internal combustion engine, such as advanced battery and flywheel concepts and the ure of hydrogen as an alternative fuel. In addition, LLNL is developing computer models 11 analyze crashworthiness, as well as to simulate the structural response of highward and bridges to seismic events. Finally, the Laboratory is participating in several partnership with the automotive industry on advanced materiais and manufacturing technologie

- Advanced manufacturing technologies. LLNL is contributing to the nation's cifun 11 improve the quality, efficiency, and environmental soundness of commerusl manufacturing processes using its expertise in precision manufacturing. Over the ris. LLNL has developed a spertrum of special facilities to support its work with unifuc materials and ultrahigh-prerision machining. These include facilities for malcmsl, Cubrication, nondestructive evaluation, and measurement and endurance testing. $1.1 \mathrm{VI}$ maintains a microtechnology laboratory, a high-pressure laboratory, and the Large ( $\mathrm{pm}$. Diamond Turning Machine, whic: sets world standards for accuracy in prewいn machining. Currently, LLNL is involved with nuinerous CRADAs in the ares it advanced materials development and development of precision manufialurmp technologies.

- Information technologies. Modern societies rely on information technologies to reduci waste by increasing the efficiency of almost all aspects commerce. Almost all III.1."r Laboratory programs push the frontiers of large-scale computing, and these cllur, provide the basis for LLNL's contributions to the advancement of informallum 
technologies. Our support of the National Information Infrastructure (NII) effort is particularly noteworthy. Congress has authorized DOE to spend \$100 million in FY 1995 in support of NII. LLNL and the other DOE laboratories are working together to develop a colierent plan for cooperative, complementary work in support of NII, capitalizing on the technical and organizational strengths of each laboratory.

One partnership activity already underway is the National Storage Laboratory, the premier center for information systems integration, standardization, and software development. It was established by and resides at LLNL's National Energy Research Supercomputer Center. The effort, in collaboration with six U.S. companies, is directed at research to commercialize technologies for high-performance computer storage of large amounts and diverse types of information. The challenge of maintaining continued U.S. leadership in magnetic mass storage is well suited to the DOE laboratories because it requires expertise in many areas from micromechanical fabrication to precision engineering and advanced materials modeling.

- Microelectronics. This is another major example of industry collaboration with the DOE laboratories. Building on their expertise in microelectronics, the laboratories are supporting technology road maps established by the Semiconductor Industry Association, the Optical Industry Development Association, and the National Storage Industry Consortium. LLNL is currently involved in several industry-driven CRADAs. For example, flat-panel displays are expected to become a $\$ 20$ billion/year business by the turn of the century, and many U.S. companies are working to develop new technologies to penetrate this currently Japanese-dominated market.

\subsection{LLNL and Strategic Challenges in Biosciences and Healthcare Technologies}

The accelerating revolution in biology and biotechnology presents another major national challenge. For the first time in history, the tools exist to decipher the genetic blueprint (DNA) and reveal the basic science of human life. This knowledge will make it possible to ameliorate, cure, or even prevent genetic diseases, enhancing the quality of life and decreasing healthcare costs. Results of this human biology research will undoubtedly carry over into agriculture, environmental management, and industry.

The Biology and Biotechnology Research Program at LLNL, supported by the DOE Office of Health and Environmental Research and other government agencies, emphasizes the development of technological solutions to problems associated with health assessment and fundarnental biology, usually at the genetic or molecular level. This program is a natural for LLNL. The research is inherently multidisciplinary, drawing not only on the life sciences but also on all the physical sciences, engineering, and computing sciences. Moreover, it benefits from special LLNL capabilities, including the Human Genome Center, the newly established Center for Healthcare Technologies and a variety of facilities that normally are not associated with biological research yet are proving pivotal to this work (e.g., accelerator mass spectrometry, lasers, and microfabrication facilities).

Biosciences research at Livermore can be divided into four main areas: genomics; structural biology; disease susceptibility; and bioinstrumentation and healthcare technologies. According to LLNL's vision statement, Framing the Laboratory's Future, the activities in each of these four areas are:

- Genomics. LLNL has one of DOE's three Human Genome Centers, which are engaged in an international effort to decipher the genetic code of the human genome. Livermore is 
responsible for developing many of the technologies that make this endeavor possible. The infrastructure developed for decoding human DNA will be applied to study genomes of plants, animals, and microorganisms on a priority basis.

- Structural biology. Here, the goal is to explore the three-dimensional structure of proteins and other biomolecules to learn how they interact with DNA. This understanding requires an extensive array of diagnostic and analytic instruments together with advanced research facilities, many of which already exist at LLNL. With the knowledge obtained, it will be possible to design or engineer specific biomolecules to improve human health and the environment.

- Disease susceptibility. LLNL scientists are undertaking a comprehensive assessment of health effects of exposures to chemicals and radiation. Methods and data developed in this assessment will lead to a science-based analysis of risk, which will facilitate important decisions regarding cost/benefit tradeoffs. The pioneering work in genomics at LLNL, coupled with state-of-the-art capabilities for detecting ultratrace levels of DNA damage, will enable Laboratory scientists to develop a better understanding of human genetic variation and the consequences of DNA damage.

- Bioinstrumentation and healthcare technology. An integral part of the Laboratory's biotechnology research is the development of advanced tools and instrumentation. The Center for Healthcare Technologies at LLNL is coordinating the Laboratory's multidisciplinary efforts in healthcare, with particular focus on minimally invasive medicine, diagnostics and imaging, microsurgical instruments, and medical information management. The work efforts are in partnership with industry, medical research institutions, healthcare providers, and government.

\subsection{Basic Science and Science Education at LLNL}

Although basic science is not a specific mission at LLNL, world-class basic science and technology flows from the Laboratory's core competencies and is pursued to solve fundamental problems that underlie programmatic work at the Laboratory. Basic science activities frequently constitute anticipatory R\&D aimed at addressing programmatic needs 5 to 10 years in the future. Basic science efforts at LLNL almost always involve mutually beneficial interactions with other laboratories, research centers, and academia. For example, in the area of space science, the Laboratory has made notable recent contributions, including work on high-temperature opacities, the Clementine lunar mapping project, the Laser Guide Star effort, and the search for dark matter.

Currently, LLNL is involved in about 600 collaborative research projects with students and faculty. Many of these projects are organized into formally recognized institutes, programs, or centers. These include: the Energetic Materials Center, the Institute of Geophysics and Planetary Physics, the Plasma Physics Research Institute, the Institute for Scientific Computing Research, the Program for Climate Model Diagnosis and Intercomparison, the Glenn T. Seaborg Institute of Transactinium Science, and the Optical Sciences Institute.

In addition, LL,NL contributes to national needs in science education. The Laboratory offers more than 60 science education programs for students and teachers at all levels. These include conferences, workshops, school-year work experience, summer work experience, tours and speakers, advisors and consultants, skill training, teacher training, and career fairs. LLNL is trying to shape the future by investing in people as well as in technology. 


\section{SUMMARY}

The DOE nuclear weapons laboratories helped win the Cold War and, in the process, provided the nation many significant scientific and technological contributions. Major advances in computer science and technology, materials science, nuclear energy, biotechnology, and environmental science can be attributed to the DOE nuclear weapons laboratories. Even among those critical of nuclear weapons work, there is general agreement that these laboratories possess unique capabilities that must be preserved and directed toward changing national priorities. They are large multipurpose laboratories capable of performing cross-disciplinary R\&D activities to solve complex applied-science problems rapidly and effectively.

This paper discusses of the role these laboratories, in general, and LLNL, in particular, can play in support of the nation's S\&T priorities. The paper also highlights some of the changes necessary to enable LLNL to effectively support both the national S\&T and economic competitiveness agendas. Exploring the nature of these changes is important to DOE and to LLNL managers responsible for the development of strategic direction and implementation plans. Investment in science and technology is critically important to resolution of a multitude of economic and environmental challenges to the U.S. A refocusing of efforts at the laboratories requires change and establishment of new or more extensive partnership arrangements with other laboratories, the DOE and other government agencies, universities, and private industry. At LLNL, the process of adjusting to the end of the Cold War is underway.

The challenge of global security - of reducing the nuclear danger-will be addressed by LLNL in partnership with DOE and its other nuclear weapons laboratories. Together, LANL, LLNL, and SNL will undertake a coordinated national program in this area and will provide for peer review of each others' work. LLNL will have lead-laboratory responsibilities in selected areas, taking advantage of the special facilities and expertise that reside at Livermore.

In other areas, new or expanded partnerships must be established to pursue national S\&T challenges vigorously. LLNL scientists and engineers have demonstrated over the decades that they can work in collaboration with universities, other research institutions, industry, and government to solve large-scale technology problems of national importance. Their recent performance in moving into new alliances with industry demonstrates that the LLNL is making the transition beyond defense and energy missions to applying its science and technology strengths in other areas for the benefit of the nation.

To address these changes and other related issues, organizational changes are underway to align program management structure so that the Laboratory can better apply its special strengths to current S\&T strategic challenges. In areas where there are special strengths, centers of excellence have been formed to coordinate strategies and activities, and as particular mission responsibilities expand, further organizational changes may become necessary. In addition, the various directorates at LLNL are:

- Developing road maps and plans of action to apply the special strengths of the Laboratory to specific S\&T strategic challenges. 
- Implementing improved processes to enable the Laboratory to work cooperatively with federal, state, and local agencies and the private sector in a more efficient and costeffective manner.

\begin{abstract}
Already engaged in projects in new mission areas, LLN' scientists and engineers are demonstrating their ability to tackle post-Cold War strategle challenges facing the nationchallenges in applied science that require long-term, multidisciplinary efforts; challenges that take advantage of the Laboratory's core competencies, special capabilities and unique facilities. In short, LLNL must no longer be viewed solely as a deferise laboratory, but as a premier national resource for medium- and large-scale science and technology demonstration. And to that end, LLNL is reaffirming its commitment to its history of public service in suppriat of the nation's S\&T priorities.
\end{abstract}




\section{REFERENCES}

1. Framing the Laboratory's Future: A vision for Lawrence Livermore National Laboratory, Lawrence Livermore National Laboratory, UCRL-AR-117362, June 1994.

2. Technology for a Sustainable Future, National Science and Technology Council, Washington, D.C., August 1994.

3. Institutional Plan FY 1994-1999, Lawrence Livermore National Laboratory, UCAR 10076-12, Decernber 1993.

4. Industrial Grand Challenges-A Competitiveness Strategy for the DOE National Laboratories, Roger W. Werne, Lawrence Livermore National Laboratory, UCRL-ID115182 , October 14, 1993.

5. FY 1996 Research and Development (R\&D) Priorities, Memorandum for the Heads of Executive Departments and Agencies, John H. Gibbons and Leon E. Panetta, The White House, May 6, 1994.

6. Defense Conversion Redirecting $R \& D$, Office of Technology Assessment, Congress of the United States, Washington, D.C., May 1993.

7. Energy \& Technology Review-The State of the Laboratory, University of California, Lawrence Livermore National Laboratory, UCRL 52000-94-1/2, January-February 1994.

8. A Rational Role for DOE National Defense Laboratories, James I. Davis and Ralph R. Jacobs, Lawrence Livermore National Laboratory, UCRL-AR-115184, July 1993.

9. Strategy White Paper-Microelectronics and Optoelectronics, A.F. Bernhardt. Lawrence Livermore National Laboratory, June 1994.

10. Strategy for Environmental Research at Lawrence Livermore National Laburutur. Jesse L. Yow, Jr, Lawrence Livermore National Laboratory, July 1994.

11. Energy White Paper, R.N. Schock, Lawrence Livermore National Laboratory. Aupun 1994.

12. Strategy White Paper for the National Information Infrastructure, Henry D) Sha Lawrence Livermore National Laboratory, June 1994.

13. Partnership can Improve Health Care, Saves Money, Health Care Techmulı'1, Lawrence Livermore National Laboratory, July 1994.

14. What Companies want from the Federal Labs, J. David Roessner, Georgia Inulfut" "1 Technology, Issues in Science and Technology, Fall 1993.

15. Retargeting the Weapons Laboratories, Siegfried S. Hecker, Issues in Scienct and Technology, Spring 1994. 

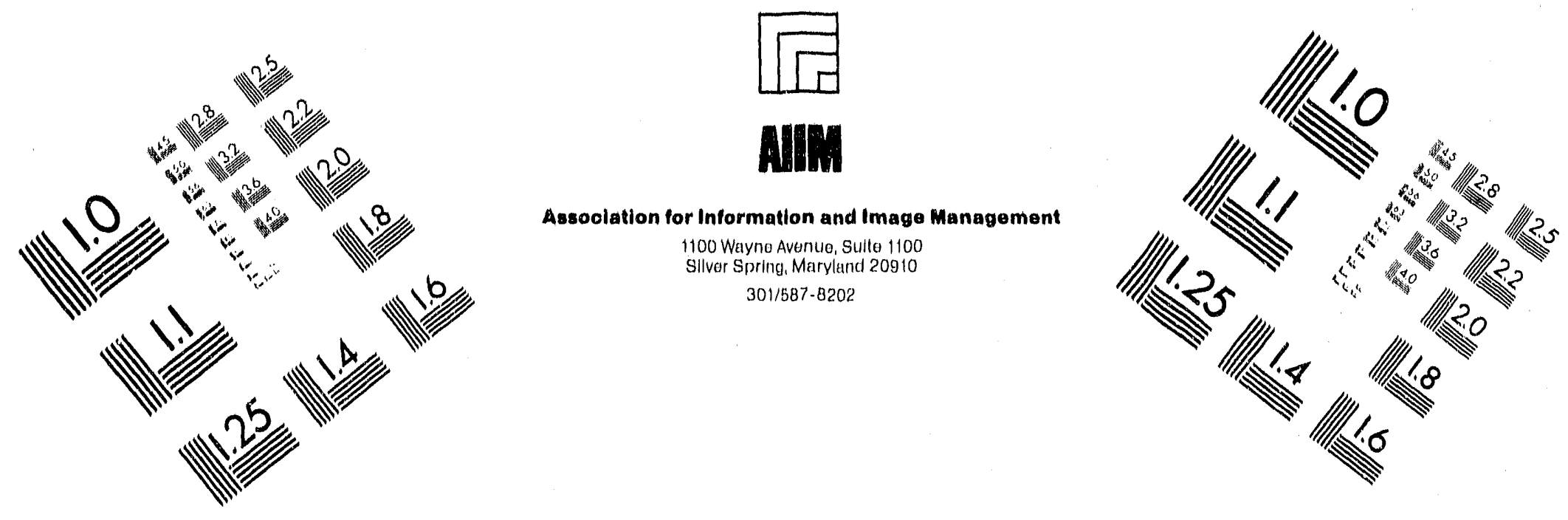

\section{Centimeter}

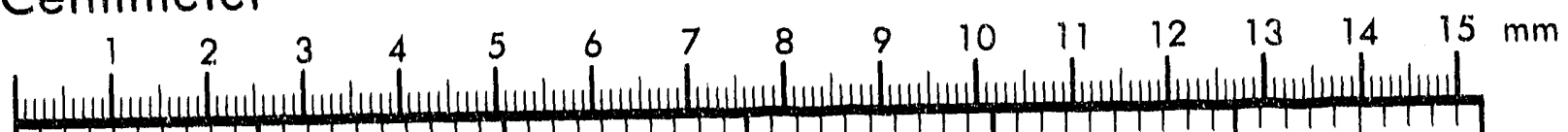

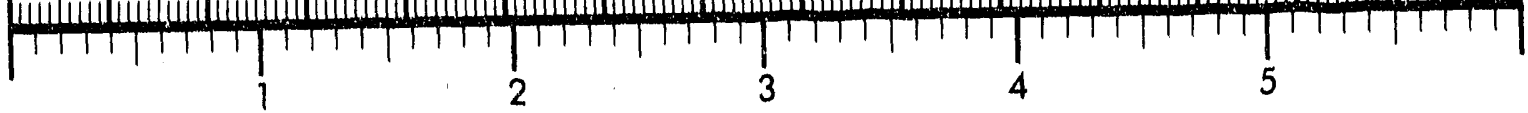
Inches
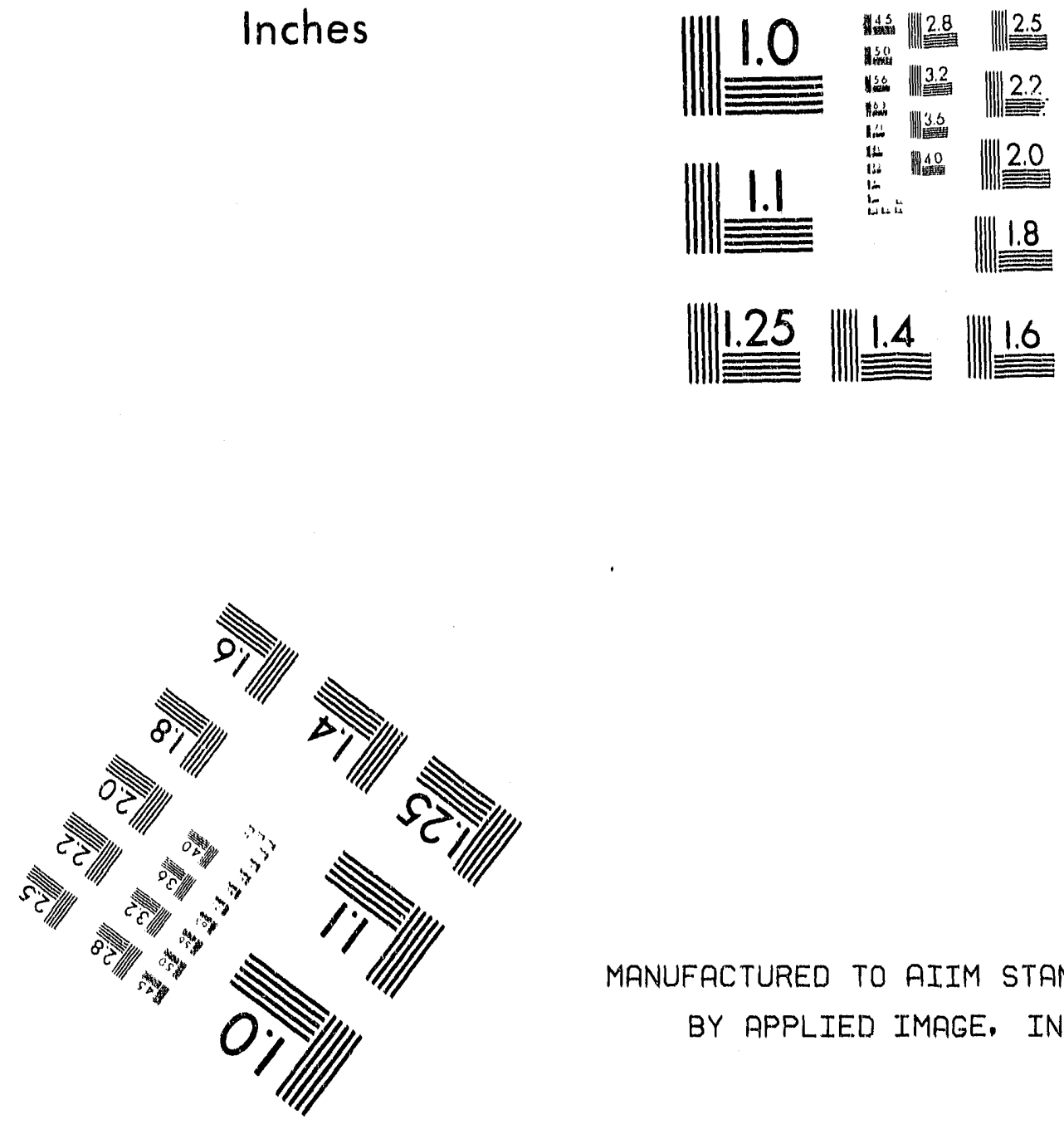

MANUFACTURED TO AIIM STANDARDS

BY APPLIED IMAGE, INC.

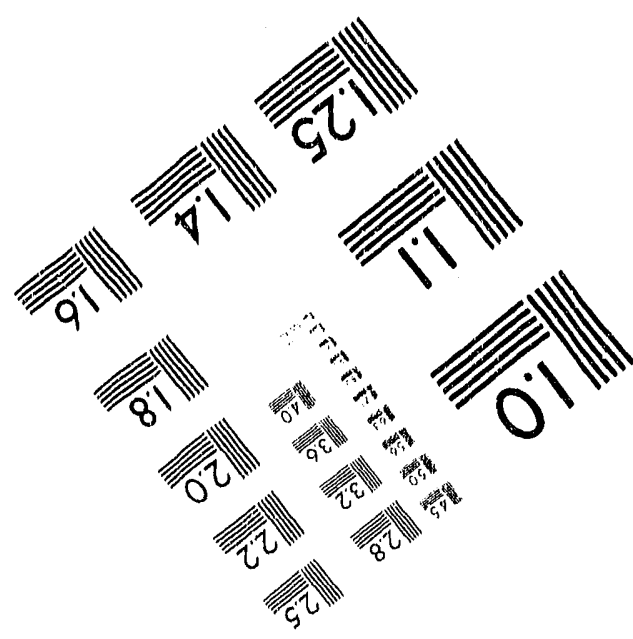



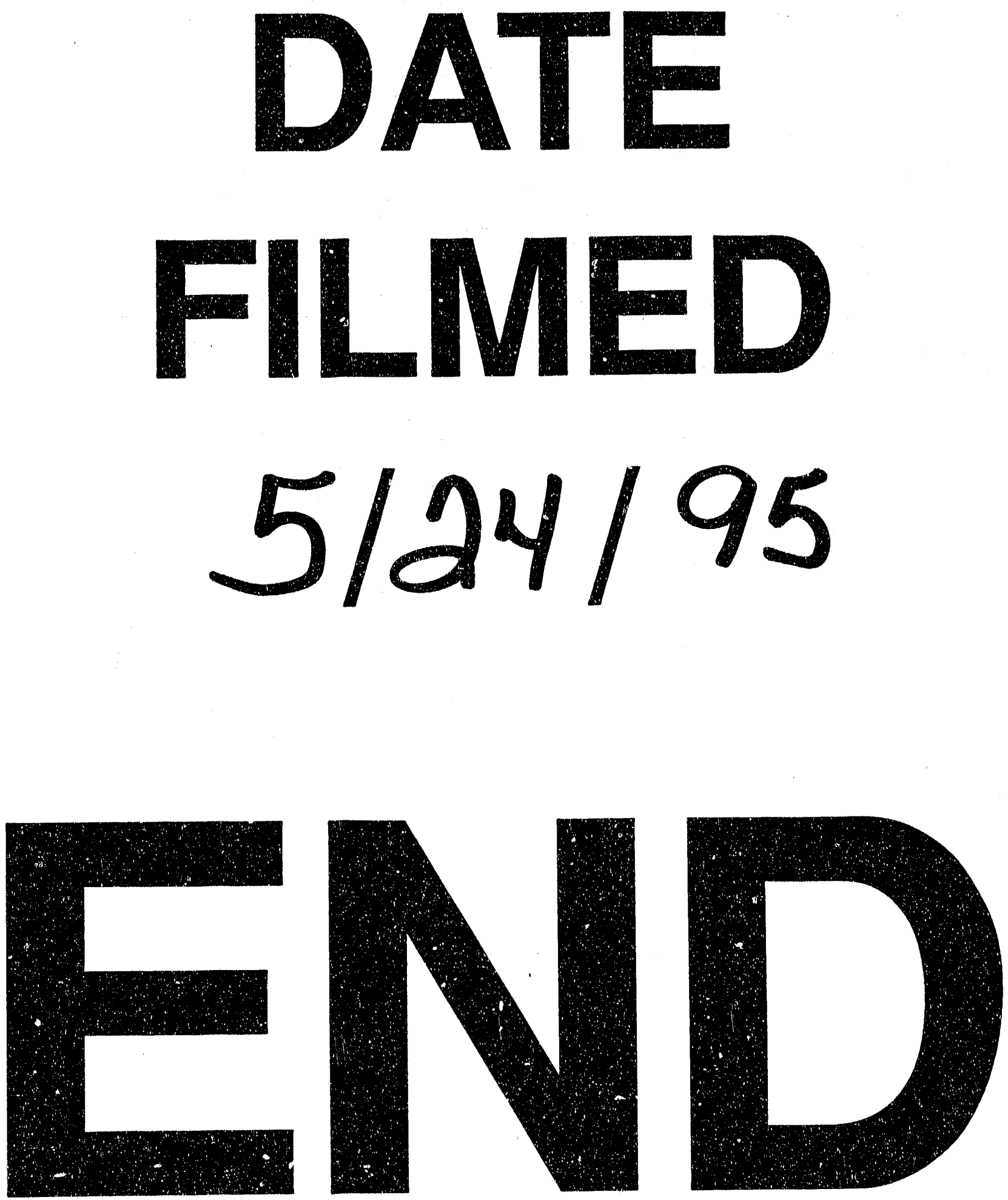